International Journal of Instruction e-ISSN: 1308-1470 • www.e-iji.net

SÁNCHEZ-ROSAS ET AL. (2021)Article submission code: 20210414141757

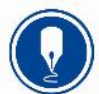

January $2022 \bullet$ Vol.15, No.1

p-ISSN: 1694-609X

pp. $985-1002$

Received: 14/04/2021

Revision: 27/08/2021
Accepted: $21 / 09 / 2021$

OnlineFirst: 10/12/2021

\title{
Collective Teacher Self-Efficacy Scale for Elementary School Teachers
}

\section{Javier Sánchez-Rosas}

Laboratorio de Evaluación Psicológica y Educativa (LEPE) - Facultad de Psicología, Universidad Nacional de Córdoba, Argentina, jsanchezrosas@unc.edu.ar

\section{Malena Dyzenchauz}

Laboratorio de Evaluación Psicológica y Educativa (LEPE) - Facultad de Psicología, Universidad Nacional de Córdoba, Argentina, malenadyzen@gmail.com

\section{Sergio Dominguez-Lara}

Universidad Privada San Juan Bautista, Lima, Perú, sergio.dominguez@ @psjb.edu.pe

\section{Agustín Hayes}

Laboratorio de Evaluación Psicológica y Educativa (LEPE) - Facultad de Psicología, Universidad Nacional de Córdoba, Argentina, agustinhayes1997@gmail.com

Collective Teacher Self-Efficacy refers to the beliefs of the faculty of a school about their ability to work as a team and achieve positive results. Although it presents itself as a promising concept related, the research is relatively scarce and the existing instruments have some limitations. The present work aims to provide new psychometric evidence for a recently created instrument. For this, an expert judgment test was carried out that evaluated content validity, and the instrument was administered to a sample of 309 subjects to analyze internal structure and testcriterion validity. Good content validity was observed, evidenced by the satisfactory evaluations of the pertinence and clarity of the items. Evidence of a five-dimensional factor structure was provided (self-efficacy for decision making, teaching, familial participation, community participation and positive school climate), with good fit indexes and internal consistency. As was expected, relationships with job satisfaction, institutional belonging, job stress, institutional commitment, and job wellbeing were found. Finally, the possible applications of the instrument are discussed.

Keywords: self-efficacy, collective efficacy, teacher efficacy, psychometrics, elementary school

\section{INTRODUCTION}

Collective teacher self-efficacy refers to the perceptions that a group of teachers of a school have regarding their ability to work together to generate a positive effect on their 
students (Goddard, Hoy, \& Hoy, 2000). This construct has been shown to have a positive relationship with a large number of variables related to teachers such as teacher commitment (Al-Mahdy et al., 2018), work satisfaction (Buonomo et al., 2020), teacher leadership (Olivier \& Hipp, 2019) and institutional belonging (Skaalvik \& Skaalvik, 2019). Collective teacher self-efficacy is also related to students variables (Coğaltay \& Karadağ, 2017; Zhang \& Yin, 2017), and institutional variables (Cansoy, 2020; Dussault et al., 2008; Karacabey et al., 2020; Lim \& Eo, 2014; Meyer et al., 2020; Qadach et al., 2020; Voelkel, 2019). The measures designed for the evaluation of collective teacher self-efficacy (Goddard, 2002; Goddard et al., 2000; Sánchez-Rosas et al. (2021), 2021; Skaalvik \& Skaalvik, 2007, 2016; Tschannen-Moran \& Barr, 2004) have theoretical and methodological limitations that, as will be observed later, suggest the need for a measure that overcomes these limitations in order to evaluate this promising construct in a reliable way. Based on the theoretical perspectives of Bandura (2006), Sánchez-Rosas et al. (2021) have developed an instrument which evaluates six dimensions of collective teacher self-efficacy whose preliminary evidence is auspicious, even though they require additional psychometric evidence. Taking into consideration this instrument (Sánchez-Rosas et al. (2021)), we have proposed to add psychometric evidence for an instrument which measures collective teacher self-efficacy in elementary school teachers.

\section{Review of Literature}

\section{Measurement of Collective Teacher Self-Efficacy}

After the teacher efficacy scale by Gibson y Dembo (1984), designed to measure individuals teacher's efficacy, Goddard et al. (2000) created the Collective Teacher Efficacy Scale (CTES) transforming the redaction of the items from an individual perspective to a group perspective using 21 items. These are categorized into two dimensions of the collective teacher self-efficacy: group competency and task analysis (Cooper, 2010). After this, Goddard (2002) created a short version of the scale with twelve items (Collective Efficacy Scale, CES).

Tschannen-Moran and Barr (2004) designed the Collective Teacher Beliefs Scale that, using 12 items, evaluates the collective perceptions of the teaching practices and teachers' capacity to influence student discipline. This bi-dimensional scale has been commonly used (Kirby \& DiPaola, 2011; Klassen et al., 2011; Leanne et al., 2019; Leithwood et al., 2019; Malinen \& Savolainen, 2016).

Skaalvik and Skaalvik (2007) designed a unidimensional instrument consisting of seven items based off of their scale of individual teacher self-efficacy (Norwegian Teacher Self-Efficacy Scale; NTSES). The subject of the items was modified from me to us or the teachers of this school.

The instruments designed by Goddard et al. (2000) and Tschannen-Moran and Barr (2004) were put together through the use of individual teacher self-efficacy scales, where the individual subject of the items was replaced with a plural one. This resulted insufficient to analyze the collective perceptions of the teaching practices and their capacity to influence student discipline which require coordination and exchange. Also, the scales by Skaalvik and Skaalvik (2016) and Tschannen-Moran and Barr (2004) ask 
about the veracity of a question or the level of agreement with a statement, instead of asking the level of security to undergo a behavior as is recommended by Bandura (2006). Also, the scales for the response of the items go from 1 to 9 (Tschannen-Moran \& Barr, 2004) or from 1 to 5 (Skaalvik \& Skaalvik, 2016), instead of using the range of 1 to 10 which is recommended by the literature (Bandura, 2006).

From its initial design, the Collective Teacher Self-Efficacy Scale developed by Sánchez-Rosas et al. (2021) looked to deal with the collective dimension of the construct and elaborated instructions and response scales for the construct. For this, the instrument includes items regarding actions which require group interaction among the group of teachers and that they respond following the recommended rules for the measurement of this type of construct (Bandura, 2006). The items in this scale have evidence of content validity and permit the evaluation of the six dimensions of the collective teacher self-efficacy proposed by Bandura (2006): self-efficacy for decision making, self-efficacy for teaching, self-efficacy for coexistence, self-efficacy for familial participation, self-efficacy for community participation, self-efficacy for the positive school climate. For the mentioned study of validity, a sample of validation with experts (researchers) and another integrated sample for the users of this measure (teachers) were used. Even though the items were well valued, the results exhibit differences in values between the two samples. The items obtained better point-values (mean, Aiken's V Coefficient, and Confidence Interval) for the sample of experts, for which the quality of the study of content validity are partially good. Even though the authors reported the modifications the items underwent after these results, the content validity was not evaluated after this, nor did they analyze other psychometric properties.

Compared to the rest of the measures (Goddard, 2002; Goddard et al., 2000; Skaalvik \& Skaalvik, 2007, 2016; Tschannen-Moran \& Barr, 2004), the Collective Teacher SelfEfficacy Scale developed by Sánchez-Rosas et al. (2021) shows a better theoretical covering of the dimensions of the construct and better methodological characteristics. However, for its use in the applied contexts or research will require additional psychometric evidence. For that, new evidence of content validity and internal structure will be analyzed; internal consistency will be esteemed, in addition to the relations of each scale with other important variables.

\section{STUDY \#1. Content Validity}

\section{METHOD}

The first study had the purpose of examining the evidence of validity based on the content in the original items of the Collective Teacher Self-Efficacy Scale (SánchezRosas et al. (2021)).

\section{Participants}

In this study there were 21 researchers and 10 elementary school teachers. Both groups evaluated the pertinence and clarity of the items, because it is possible to find discrepancies within the perception of the items between the objective sample of the instrument and the determined experts (Merino-Soto, 2016; cited from Dominguez-Lara, 2017). 


\begin{abstract}
Measure
Collective Teacher Self-Efficacy Scale (Sánchez-Rosas et al. (2021)). This is a selfreport instrument which measures the beliefs regarding the capacities of the team of teachers. Specifically, it was designed to evaluate, through the use of 45 items, six dimensions of collective teacher self-efficacy: self-efficacy for decision making (8 items), self-efficacy for teaching ( 8 items), self-efficacy for coexistence ( 7 items), selfefficacy for familial participation ( 7 items), self-efficacy for community participation ( 7 items), and self-efficacy for the positive school climate (8 items). The responses to these items were recorded in a Likert scale to indicate the grade in which teachers think they can succeed in these constructs from (1) not at all sure that we can do it to (10) totally sure that we can do it.
\end{abstract}

\title{
Procedure
}

Given that the modified items and results of the scale (Sánchez-Rosas et al. (2021)) did not show new evidence of content validity, the items were submitted to a test carried out by experts and teachers. A group of researchers as well as teachers evaluated the clarity and pertinence of the scale, understanding that an item would be understandable or clear if it did not admit more than one possible interpretation. It was also considered pertinent if it could represent the information that was being searched. A scale with 5 points was used from bad (1) to excellent (5).

The participants were informed about the objectives of the study, it was recorded that the information collected would exclusively be used with academic and research purposes, and that their participation was completely voluntary. In addition to this, they were informed that the data would be anonymous and confidential.

\section{Data Analysis}

Before anything else, the mean value of each item for each of the two samples was calculated. For the quantification of the grade of agreement between the judges the Aiken's V Index and its Confidence Intervals (CI; Merino-Soto \& Livia Segovia, 2009) was used, expecting values greater than .50 for the lower limit of the CI (Dominguez Lara, 2017). On the other hand, to analyze the CI of the difference between the Aiken's V Index of experts and teachers a procedure recommended by Merino-Soto (2018) was used which considered the existence of a significant difference of the CI did not include the value 0 . In a complementary way, the statistical significance for each $\mathrm{V}$ was estimated according to the proposal of Aiken (1985). The present results were compared with those of the analysis carried out by Sánchez-Rosas et al. (2021) to verify if better results were obtained.

\section{FINDINGS}

Table 1 shows the comparison between the obtained results in the study done by Sánchez-Rosas et al. (2021) and those obtained in the present analysis. This table shows the averages per dimension of the mean and the Aiken's V Coefficient of each item (in accordance with its clarity and pertinence), including statistical significance. Also, the table shows the average per dimension of the confidence intervals and the differences 
between the confidence intervals for teachers and researchers. The detailed point values of each of these items in each analysis were omitted to simplify the presentation and because of limitations of space.

Table 1

Comparative expert judgments for teachers and researchers by dimension of collective teacher self-efficacy

\begin{tabular}{|c|c|c|c|c|c|c|c|c|c|c|c|c|c|}
\hline Dimension & Teac & ichers & & & & & Res & earche & & & & Differ & ences \\
\hline & & $M_{1} \quad M_{2}$ & $\mathrm{~V}_{1}$ & $\mathrm{~V}_{2}$ & CI $95 \% 1$ & $\begin{array}{l}\mathrm{CI} \\
95 \% 2\end{array}$ & $\mathrm{M}_{1}$ & $\mathrm{M}_{2}$ & $\mathrm{~V}_{1}$ & $\mathrm{~V}_{2}$ & $\begin{array}{l}\text { CI CI } \\
95 \% 1 \\
95 \% 2\end{array}$ & $\begin{array}{l}\mathrm{CI} \\
\mathrm{V}_{\mathrm{T}}- \\
\left.\mathrm{V}_{\mathrm{R}}\right)_{1}\end{array}$ & $\begin{array}{l}\left(\mathrm{CI} \mathrm{V}_{\mathrm{T}}-\right. \\
\left.\mathrm{V}_{\mathrm{R}}\right)_{2}\end{array}$ \\
\hline & MP & 3.634 .46 & .65 & $.86^{* * *}$ & $.50-.77$ & $.72-.93$ & 4.86 & 4.70 & $.96^{* *}$ & $.92^{* *}$ & $\begin{array}{ll}.89- & .84- \\
.98 & .95\end{array}$ & $\begin{array}{l}-.46 ; \\
-.16\end{array}$ & $-.04 ; .20$ \\
\hline SMD & MC & 3.734 .32 & .68 & $.82 * *$ & $.52-.79$ & $.68-.91$ & 4.43 & 4.67 & $.85^{* *}$ & $.91^{* *}$ & $\begin{array}{ll}.75- & .83- \\
.91 & .95 \\
\end{array}$ & $\begin{array}{l}-.34 \\
.01 \\
\end{array}$ & $-.02 ; .24$ \\
\hline ST & MP & 4.074 .55 & $.76^{*}$ & $.88 * *$ & $.61-.86$ & $.74-.94$ & 4.85 & 4.78 & $.95^{* *}$ & $.94 * *$ & $\begin{array}{ll}.88- & .87- \\
.98 & .97\end{array}$ & $\begin{array}{l}-.34 \\
-.06\end{array}$ & $-.03 ; .19$ \\
\hline S1 & MC & 4.124 .46 & $.77 *$ & $.86^{* * *}$ & $.62-.87$ & $.72-.93$ & 4.50 & 4.76 & $.87 * *$ & $.93 * *$ & $\begin{array}{ll}.77- & .86- \\
.92 & .96\end{array}$ & $\begin{array}{l}-.25 \\
.04\end{array}$ & $-.02 ; .22$ \\
\hline SC & MP & 4.114 .57 & $.77 *$ & $.89 * *$ & $.62-.87$ & $.75-.95$ & 4.91 & 4.92 & $.97 * *$ & $.97 * *$ & $\begin{array}{ll}.90- & .92- \\
.99 & .98 \\
\end{array}$ & $\begin{array}{l}-.34 ; \\
.06 \\
\end{array}$ & $0 ; .22$ \\
\hline$x$ & $\mathrm{MC}$ & 4.084 .48 & $.76^{*}$ & $.87 * *$ & $.62-.86$ & $.72-.93$ & 4.48 & 4.74 & $.86^{* *}$ & $.93 * *$ & $\begin{array}{ll}.77- & .86- \\
.92 & .96\end{array}$ & $\begin{array}{l}-.26 \\
.04 \\
\end{array}$ & $-.03 ; .21$ \\
\hline SEP & MP & 3.854 .78 & $.71 *$ & $.94 * *$ & $.55-.82$ & $.83-.97$ & 4.79 & 4.84 & $.94 * *$ & $.95^{* *}$ & $\begin{array}{ll}.86- & .89- \\
.97 & .97 \\
\end{array}$ & $\begin{array}{l}-.39 \\
-.09\end{array}$ & $-.03 ; .16$ \\
\hline $\mathrm{SFF}$ & MC & 3.914 .67 & $.72 *$ & $.91 * *$ & $.57-.83$ & $.79-.96$ & 4.50 & 4.71 & $.87^{* *}$ & $.92 * *$ & $\begin{array}{ll}.77- & .84- \\
.92 & .95\end{array}$ & $\begin{array}{l}-.31 \\
0\end{array}$ & $-.04 ; .17$ \\
\hline SCP & MP & 4.014 .70 & $.75^{*}$ & $.92 * *$ & $.60-.85$ & $.79-.97$ & 4.84 & 4.80 & $.96^{* *}$ & $.94 * *$ & $\begin{array}{ll}.88- & .88- \\
.98 & .97 \\
\end{array}$ & $\begin{array}{l}-.35 \\
-.08 \\
\end{array}$ & $-.05 ; .15$ \\
\hline SCP & MC & 4.014 .64 & $.75^{*}$ & $.90 * *$ & $.59-.85$ & $.77-.96$ & 4.48 & 4.78 & $.86^{* *}$ & $.94 * *$ & $\begin{array}{ll}.76- & .87- \\
.92 & .97\end{array}$ & $\begin{array}{l}.28 \\
.02\end{array}$ & $-.06 ; .16$ \\
\hline SPC & MP & 4.214 .68 & $.80^{* *}$ & $.91 * *$ & $.65-.89$ & $.79-.96$ & 4.73 & 4.72 & $.93^{* *}$ & $.92 * *$ & $\begin{array}{ll}.84- & .85- \\
.96 & .96 \\
\end{array}$ & $\begin{array}{l}-.28 \\
0 \\
\end{array}$ & $-.07 ; .14$ \\
\hline SPC & $\mathrm{MC}$ & 4.174 .67 & $.79^{* *}$ & $.91 * *$ & $.64-.88$ & $.80-.96$ & 4.50 & 4.72 & $.87^{* *}$ & $.92^{* * *}$ & $\begin{array}{ll}.77- & .85- \\
.92 & .96\end{array}$ & $\begin{array}{l}-.16 \\
.05\end{array}$ & $-.06 ; .15$ \\
\hline
\end{tabular}

Note. $* \mathrm{p}<.05 ; * * \mathrm{p}<.01 ; \mathrm{MP}=$ Mean values for Pertinence; $\mathrm{MC}=$ Mean values for Clarity; $\mathrm{M}=$ mean; $\mathrm{V}=\mathrm{V}$ of Aiken; $\mathrm{CI}=$ confidence intervals; $\mathrm{V}_{\mathrm{T}}=\mathrm{V}$ of Aiken for teachers; $\mathrm{V}_{\mathrm{R}}=\mathrm{V}$ of Aiken for researchers. SMD = self-efficacy for decision making, ST $=$ self-efficacy for teaching, $\mathrm{SC}=$ self-efficacy for coexistence, $\mathrm{SFP}=$ self-efficacy for familial participation, SCP = self-efficacy for community participation, and SPC = selfefficacy for the positive school climate. The subscript 1 indicates that the results pertain to Sánchez-Rosas et al. (2021). The subscript 2 indicates that the results pertain to the present analysis.

\section{DISCUSSION}

The results effectively show that the items modified by Sánchez-Rosas et al. (2021) were valued more positively in the present research, especially in the case of the sample of the teachers. In the preceding research project, the Aiken's V coefficient also improved in most cases, predominantly with the sample of teachers. The confidence intervals also improved, surpassing the limit of .50 and the differences between the values of both were reduced, which means that the modifications undergone in the items made them more comprehensible for their target population. In general, the statistics 
provide evidence which is favorable to the validity of the items in relation to their clarity and pertinence so as to measure the dimensions of collective teacher self-efficacy in question.

\section{STUDY \#2. Structural Validity, Test-Criterion Validity, and Internal Consistency}

The purpose of the second study was to analyze the internal structure of the items, the internal consistency, the relation of the scales with other variables, and to explore the differences in function of some variables regarding both teachers and institutions.

\section{METHOD}

\section{Participants}

This study used a convenience sample of 309 elementary school teachers in Argentina. In $94.2 \%$ of the cases pertained to people who identify as female and $5.8 \%$ were people who identify as male, which accurately reflects the teachers in the reference country. The mean age of participants was of 41.2 years $(S D=8.67)$. On the other hand, the mean of years spent working as a teacher was $12.2(\mathrm{SD}=8.05)$

Among the total sample, some $81.2 \%$ taught traditional subjects (English, Math, Social Studies, and Science) and the remaining $17.8 \%$ taught special subjects (physical education, music, art, foreign languages, computer skills, and others). Right at $78 \%$ of the sample worked at just one school while $15.9 \%$ worked in two, and $6.1 \%$ worked in three or more schools. Lastly, some $72.5 \%$ of the institutions were public and the remaining $27.5 \%$ were private.

\section{Measures}

Collective Teacher Self-Efficacy Scale (Sánchez-Rosas et al. (2021)). This measure refers to the same thing used in the first study, with the same quantity and distribution of items per dimensions. The final version of this measure is presented in the appendix.

Criterion Variables. Five unique items were written up to evaluate job satisfaction (I feel satisfied with my work at this school), institutional belonging (I feel as though I am a part of this school), job stress (My job at this school causes me occasional stress), institutional commitment (I feel committed to my job at this school), and job wellbeing (When I am working at this institution I feel good). The response scale ranged from 1 (do not agree at all) to 5 (totally agree). As an additional and condensed measure, a latent dependent variable was modeled which explained this group of variables, specifying a relationship between the errors of stress and wellbeing, $\left[\chi^{2}(4, N=309)=\right.$ $\left.10.11, \mathrm{p}=.04, \chi^{2} / \mathrm{df}=2.52, \mathrm{CFI}=.99, \mathrm{GFI}=.99, \mathrm{RMSEA}=0.070\right]$ and this showed good internal consistency $(\alpha=.79)$.

\section{Procedure}

An online survey was put together whose link was sent out through email, or social media (Facebook messenger or WhatsApp). The teachers were also explained the objective of this study and the importance of their contribution. Lastly, they were 
informed that their participation was completely voluntary and anonymous and that their personal data would be confidential and only used for research purposes.

\section{Analysis of Data}

Toward the end of executing the internal structure study of the Collective Teacher Selfefficacy Scale an exploratory structural equation modeling was carried out (ESEM; Asparouhov \& Muthen, 2009) with the method of robust maximum likelihood estimation with a base in the matrix of Pearson correlations, being completed with goemin rotations $(\varepsilon=.05$; Asparouhov \& Muthen, 2009).

The possibility of executing an analysis that is purely exploratory was denied because it contemplated a theoretical initial structure and, consequentially, a confirmatory factor analysis was used. However, some inaccurate specifications associated with the crossloads that were not specified were generated, these affected the CFI and inflated the RMSEA which is expected due to the complexity which characterizes this model so much as it does any other model of self-efficacy. In accordance with the current recommendations (Lloret-Segura et. al, 2014), the most applicable in these cases is an ESEM.

The quality of the examined model was analyzed with different criterion. The first was based on the magnitude of the fit indexes CFI ( $>$.90; McDonald \& Ho, 2002), the upper limit of the confidence interval of the RMSEA ( $<0.10$; West, Taylor, \& Wu, 2012), and the SRMR $(<0.08 ; \mathrm{Hu} \&$ Bentler, 1999). The second criterion was based on the representativity of the construct at the level of the items while considering the magnitude of the principal loads, that is to say, of the items in their theoretic factor, expecting values larger than .60 (Dominguez-Lara, 2018); and the magnitude of the secondary loads were evaluated with the index of factorial simplicity (IFS; Fleming \& MerinoSoto, 2005). Consequentially, it can be concluded that the item is predominantly influenced by a singular factor when the values obtained are greater than .70 . The third criterion was based on the differentiation between factors, which was evaluated comparing the average variance extracted (AVE), or the variance explained by each factor, with the square of the inter-factorial correlation $\left(\phi^{2}\right)$, which would represent the shared variance between the factors. Higher values of AVE are expected with respect to the shared variance.

Lastly, the level of confidence of the construct was estimated with the coefficient $\omega$ (> .70; Hunsley \& Marsh, 2008), because it is less influenceable due to the difference between the factor loads and more appropriate for the co-generic measures than the coefficient $\alpha$ (Dominguez-Lara \& Merino-Soto, 2018).

To contribute evidence of test-criterion validity, bivariate correlations between the observed point values of the factors of collective teacher self-efficacy were analyzed and each one of the five items considered (satisfaction, belonging, stress, commitment, and wellbeing) through Pearson's $r$ coefficient. Also, a path analysis where the simultaneous effects of the factors of self-efficacy was analyzed regarding a latent variable which explained the behavior of the five criterion items. To analyze the adjustment of the model, the fit indexes were interpreted along with the significance of the path 
coefficients (Pérez et al., 2014). Altogether, the expectation was that positive relationships between the dimensions of the collective teacher self-efficacy, the items, and the modeled variable, except stress which was expected to be related negatively.

As a last step, with the purpose of exploring if the different dimensions of collective teacher self-efficacy differed between groups, $t$ tests were applied for independent samples, considering that the differences would be significant with a level of significance $<.05$. The continued variables (age, years working at the school) were correlated with the Person's r coefficient.

\section{FINDINGS}

\section{Analysis of the internal structure and consistency}

Initially an oblique six factor model was evaluated, which corresponded to the initial proposal of the measure. The fit indexes were acceptable CFI $=.92$; RMSEA $=0.062$, CI 90\% 0.058, 0.066; SRMR = 0.018). Nevertheless, some factor loads showed evidence of magnitudes which were relatively low (items 17, 20, 22, 23, 28, 44 y 45), some items did not correspond with their theoretic factor (items 17 and 23) or they were complex items (items 4, 20, 21, 22, 28, 29, 30, 44 and 45).

After the second analysis which disposed of items 17 and 23 because they do not pertain to the theoretical factor, and that of items $4,20,21,22,28,29,30,44$ and 45 for presenting factorial complexity, the model was presented with a better adjustment (CFI $=.94 ; \mathrm{RMSEA}=0.061, \mathrm{CI} 90 \% 0.055,0.067 ; \mathrm{SRMR}=0.015)$ and from moderate to elevated factor loads, but the factor of scholarly coexistence only maintained two items (items 18 and 19), which is why it was eliminated. Meanwhile, item 34 was also eliminated for being a Heywood case $(\lambda=1.01)$.

A third factorial analysis was then done with the remaining 31 items, which considered five factors. The fit indexes were also acceptable $(\mathrm{CFI}=.95$; RMSEA $=0.060, \mathrm{CI} 90 \%$ $0.054,0.066$; SRMR $=0.016$ ), also presenting from moderate to elevated factor loads $(>$ .50 ), acceptable factorial simplicity in the majority of items (an item has an IFS greater than .65 , but the second most elevated load is close to .20 and, because of this, would not be significant), good discriminative capacity between factors, given that the AVE (> .50 in each factor) is greater than the shared variance between factors $\left(\phi^{2}\right)$ in the majority of cases, and elevated reliability in the construct $(\omega>.80)$.

After this, and with the idea of gaining a homogenous version with regards to the number of items, the four with the greatest factor loads were selected from each dimension (except self-efficacy for familial participation which already had four). In the factor self-efficacy for decision making items 1, 2, 6, and 7 were considered. In the factor self-efficacy for teaching items 9, 10, 11, and 13 were conserved. In the factor self-efficacy for community participation items 31, 32, 33, and 34 were considered. Lastly, with regards to self-efficacy for the positive school climate the items 38, 39, 40, and 42 were conserved.

Finally, a new structure of five factors with four items was evaluated per factor which showed fit indexes of an acceptable magnitude (CFI $=.97$; RMSEA $=0.062$, CI 90\% $0.051,0.067$; SRMR $=0.012)$, and with similar characteristics to the previous model: 
elevated factor loads $(>.50)$, factorial simplicity in all of the items (IFS $>.70)$ and a good discriminative capacity between factors (AVE $>\phi^{2}$ ) (Table 2). The reliability level of the factors, which were evaluated with the coefficient omega, was good in each case (>.81).

Table 2

Structural analysis of the collective teacher self-efficacy scale

\begin{tabular}{|c|c|c|c|c|c|c|c|c|c|c|}
\hline & $\mathrm{F} 1$ & $\mathrm{~F} 2$ & F3 & $\mathrm{F} 4$ & F5 & IFS & $\mathrm{M}$ & SD & SK & $\mathrm{KU}$ \\
\hline \multicolumn{11}{|l|}{ F1 } \\
\hline Item 1 & .84 & .01 & .01 & .01 & .06 & .99 & 7.39 & 2.07 & -0.96 & 0.62 \\
\hline Item 2 & .88 & .05 & -.06 & -.03 & .09 & .97 & 7.57 & 1.87 & -0.95 & 0.61 \\
\hline Item 6 & .76 & .01 & .08 & .11 & .01 & .96 & 7.14 & 2.22 & -0.96 & 0.53 \\
\hline Item 7 & .78 & .01 & .10 & .11 & -.10 & .93 & 7.26 & 2.14 & -1.05 & 0.71 \\
\hline \multicolumn{11}{|l|}{ F2 } \\
\hline Item 9 & .14 & .75 & -.05 & -.02 & .09 & .92 & 7.84 & 1.88 & -1.24 & 1.56 \\
\hline Item 10 & -.05 & .90 & .01 & .04 & .03 & .99 & 7.57 & 1.98 & -1.09 & 1.12 \\
\hline Item 11 & .01 & .88 & .06 & .01 & -.04 & .99 & 7.65 & 1.99 & -1.14 & 1.09 \\
\hline Item 13 & .05 & .72 & .11 & .06 & .01 & .95 & 7.47 & 1.92 & -1.06 & 0.88 \\
\hline \multicolumn{11}{|l|}{ F3 } \\
\hline Item 24 & -.10 & .13 & .74 & .12 & .01 & .90 & 7.25 & 2.13 & -1.00 & 0.71 \\
\hline Item 25 & .06 & -.06 & .79 & .10 & .06 & .95 & 7.40 & 2.08 & -1.17 & 1.29 \\
\hline Item 26 & .01 & .07 & .88 & -.03 & -.03 & .98 & 7.53 & 2.00 & -1.16 & 1.34 \\
\hline Item 27 & .04 & -.01 & .87 & -.03 & .08 & .98 & 7.57 & 2.05 & -1.29 & 1.49 \\
\hline \multicolumn{11}{|l|}{ F4 } \\
\hline Item 31 & .02 & -.01 & .04 & .80 & .05 & .98 & 6.75 & 2.24 & -0.87 & 0.32 \\
\hline Item 32 & .07 & .09 & .02 & .65 & .08 & .93 & 7.14 & 2.21 & -0.93 & 0.53 \\
\hline Item 33 & .01 & .05 & -.01 & .92 & -.05 & .99 & 6.83 & 2.29 & -0.85 & 0.20 \\
\hline Item 35 & .01 & -.01 & .01 & .80 & .07 & .98 & 6.86 & 2.21 & -0.86 & 0.33 \\
\hline \multicolumn{11}{|l|}{ F5 } \\
\hline Item 38 & -.01 & .03 & .02 & .16 & .78 & .94 & 7.93 & 1.90 & -1.53 & 2.77 \\
\hline Item 39 & -.01 & -.03 & .00 & .05 & .96 & .99 & 8.17 & 1.78 & -1.62 & 3.06 \\
\hline Item 40 & .09 & .05 & .23 & .08 & .49 & .72 & 7.64 & 2.06 & -1.29 & 1.44 \\
\hline Item 42 & .09 & .11 & .17 & -.06 & .61 & .84 & 8.21 & 1.84 & -1.70 & 3.40 \\
\hline$\Omega$ & .89 & .89 & .89 & .87 & .81 & & & & & \\
\hline AVE & .67 & .67 & .68 & .64 & .54 & & & & & \\
\hline $\mathrm{F} 1$ & - & .42 & .43 & .36 & .46 & & 7.34 & 1.91 & -1.07 & 0.86 \\
\hline $\mathrm{F} 2$ & .65 & - & .53 & .53 & .54 & & 7.63 & 1.80 & -1.21 & 1.37 \\
\hline F3 & .65 & .72 & - & .63 & .56 & & 7.44 & 1.93 & -1.22 & 1.51 \\
\hline $\mathrm{F} 4$ & .60 & .73 & .79 & - & .51 & & 6.90 & 2.05 & -0.96 & 0.70 \\
\hline F5 & .67 & .73 & .74 & .71 & - & & 7.99 & 1.75 & -1.70 & 3.38 \\
\hline
\end{tabular}

Note. IFS: Index of factorial simplicity; $\omega$ : omega coefficient; AVE: Average Variance Explained. Under the diagonal in the bottom part of the table is the correlation between factors, and on top of that the shared variance. F1= self-efficacy for decision making; F2 = self-efficacy for teaching; F3 = self-efficacy for familial participation; F4 = selfefficacy for community participation; F5 = self-efficacy for the positive school climate. M: mean, SD: Standard Deviation, SK: skewness, KU: kurtosis.

\section{Evidence of Test-Criterion Validity}

As can be seen in table 3, all of the factors showed significant correlations with each of the selected variables as criterion. As was expected, positive relationships were found 
between each of the factors and the items that evaluated satisfaction, belonging, commitment, and wellbeing. On the other hand, and as expected, negative relationships were found between job stress and each of the factors of self-efficacy.

Table 3

Correlations between the factors and criterion variables

\begin{tabular}{|c|c|c|c|c|c|c|c|c|c|c|}
\hline & 1 & 2 & 3 & 4 & 5 & 6 & 7 & 8 & 9 & 10 \\
\hline 1. Satisfaction & - & & & & & & & & & \\
\hline 2. Belonging & $.64 * *$ & - & & & & & & & & \\
\hline 3. Stress & $-.31 * *$ & $-.31 * *$ & - & & & & & & & \\
\hline 4. Commitment & $.44 * *$ & $.54 * *$ & $-.13 *$ & - & & & & & & \\
\hline 5. Wellbeing & $.60 * *$ & $.72 * *$ & $-.50 * *$ & $.40 * *$ & - & & & & & \\
\hline 6. SMD & $.42 * *$ & $.52 * *$ & $-.31 * *$ & $.27 * *$ & $.45 * *$ & - & & & & \\
\hline 7.ST & $.43 * *$ & $.48 * *$ & $-.35 * *$ & $.26 * *$ & $.50 * *$ & $.69 * *$ & - & & & \\
\hline 8. SFP & $.44 * *$ & $.50 * *$ & $-.32 * *$ & $.29 * *$ & $.51 * *$ & $.68 * *$ & $.75 * *$ & - & & \\
\hline 9. SCP & $.38 * *$ & $.48 * *$ & $-.29 * *$ & $.24 * *$ & $.45 * *$ & $.66 * *$ & $.75 * *$ & $.80 * *$ & - & \\
\hline 10. SPC & $.48 * *$ & $.55^{* *}$ & $-.37 * *$ & $.25 * *$ & $.55 * *$ & $.73 * *$ & $.78^{* * *}$ & $.80 * *$ & $.77 * *$ & - \\
\hline
\end{tabular}

Note. $* \mathrm{p}<.05, * * \mathrm{p}<.01 . \mathrm{SMD}=$ self-efficacy for decision making, ST $=$ self-efficacy for teaching, SFP = self-efficacy for familial participation, $\mathrm{SCP}=$ self-efficacy for community participation, and SPC = self-efficacy for the positive school climate.

Additionally, the adjustment of the predictive model of the different dimensions of collective teacher self-efficacy was analyzed, which showed a good fit to the data: $\chi^{2}$ $(24, \mathrm{~N}=309)=46.42, p=.01, \chi^{2} / d f=1.93, C F I=.99, G F I=.97, R M S E A=0.055$. Figure 1 shows the direct standardized effects of each dimension of collective teacher self-efficacy regarding the latent dependent variable (44\% of variance explained), which at the same time explains the five criterion items. All of the effects and relations were significant, with the exception of the effects of self-efficacy for teaching, self-efficacy for familial participation and self-efficacy for community participation.

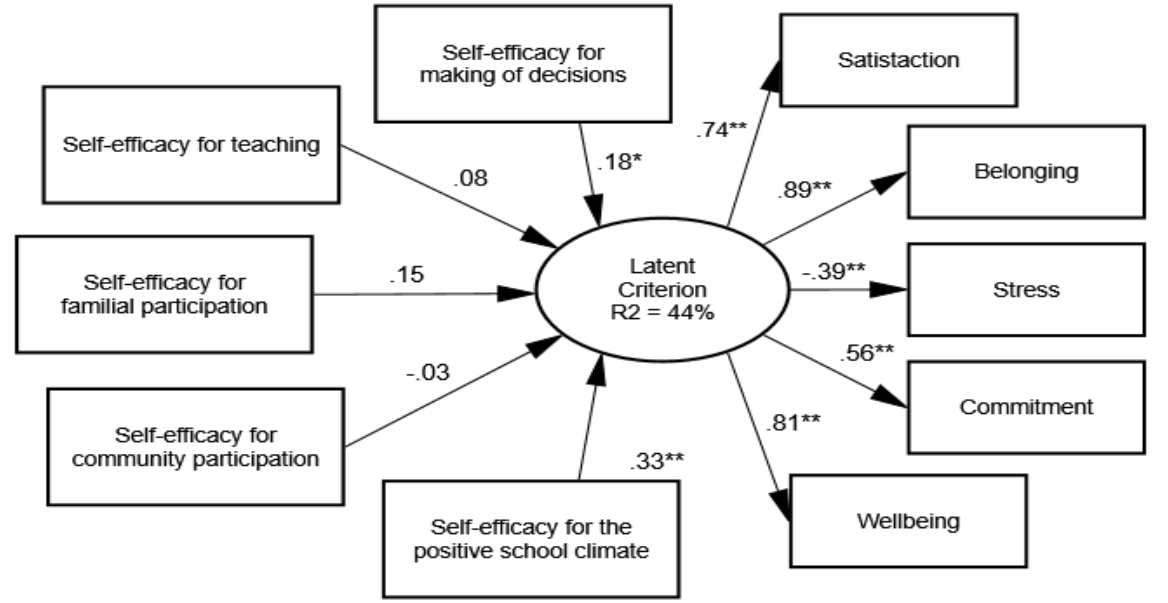

Figure 1

Standardized effects of each dimension of collective teacher self-efficacy Note. $* \mathrm{p}<.05, * * \mathrm{p}<.01$. 


\section{Collective teacher self-efficacy in accordance to groups and relation with age and years of teaching}

There were no differences according to gender, whether they work in a private or public school, type of class taught, nor number of institutions that the teacher works at for any of the factors with scales. There were no significant correlations with the age of the teachers nor with the amount of years they had been teaching on any of the factors.

\section{DISCUSSION}

The results showed evidence of a five dimensional structure (the factor Self-efficacy for Coexistence was eliminated). Some items were eliminated for having low or crossed factor loads, and others for being able to get a scale that is more parsimonious and homogenous with regards to the quantity of items per dimension. The final scale ended up being composed of 20 items (five dimensions with four items each). This structure showed fit indexes of an acceptable magnitude, with elevated factor loads, factorial simplicity in all of the items and a good discriminative capacity between factors. The reliability of each of the factors was also good. This implies that the final structure is fitted to the data and reliable.

With respect to the evidence of the relationship with other variables, it was verified that all of the factors showed significant and positive relationships with the criterion variables of job satisfaction, sense of belonging, teacher commitment, and professional wellbeing, but negative relationships with job stress. However, the path analysis showed that only the factors of self-efficacy for decision making and self-efficacy for the positive school climate showed significant positive relationships.

Finally, there were no differences found in the levels of collective teacher self-efficacy due to gender, whether they're at a public or a private school, class they teach, amount of institutions where they work, and years of teaching.

\section{DISCUSSION}

The reported studies permit a recollection of satisfactory psychometrics evidence for the Collective Teacher Self-efficacy Scale (Sánchez-Rosas et al. (2021)). A strong content validity and test-criterion validity were observed. At the same time the factor structure of five dimensions presented good fit indexes, factorial simplicity, average variance explained and internal consistency.

Even though the analysis begun with a group of items which were results of a previous study (Sánchez-Rosas et al. (2021)), the changes which had occurred in them (like adjustments to the response command, extension of the items or clarity of the terms that were used) had not been appropriately validated, which justified a new analysis with the end goal of continuing further study. The use of expert researchers and teachers (Merino-Soto, 2018) that simultaneously validated the clarity and pertinence of the items, permitted the transcendence of partial approaches used for the validating of other scales (Goddard et al., 2000; Tschannen-Moran \& Barr, 2004). The differences found between point values obtained by researchers and teachers, evaluated with regards to the 
difference in the confidence intervals for the $\mathrm{V}$ of Aiken, were notably reduced and the quality informed was high for all of the items.

The scales that were designed by other researchers (Goddard et al., 2000; Goddard, 2002; Tschannen-Moran \& Barr, 2004) considered simple dimensional structures. To contrast that, the multiple dimensions of this study were derived from propositions recommended by Bandura (2006) for the individual teacher self-efficacy. The results showed a five dimensional structure.

The dimension of self-efficacy for coexistence needed to be eliminated, mainly because its items presented low factor loads or factor loads that were crossed with others such as familial participation, community participation, or positive scholarly climate. These results could indicate that there are aspects of scholarly coexistence which find themselves overlapping with information relative to parental involvement and the community of the school, and especially with the actions that are put to use to generate a positive scholarly climate. Nonetheless, in future studies the eliminated dimension could be re-formulated and re-incorporated, limiting the reach from some way or another and making a thorough distinction from the rest of the dimensions. This would be necessary because the relational aspects of scholarly coexistence play an important role in the idiosyncrasy of the institutions of our country.

On the other hand, studies of test-criterion validity were executed, verifying the relationship of the dimensions with other constructs that found themselves in relation with collective teacher self-efficacy in the existing literature. In the first analysis all of the factors showed significant positive relationships with the criterion variables of job satisfaction, feeling of belonging, teacher commitment, and job wellbeing, and a negative relationship with job stress. Instead, this study executed a path analysis with the idea of identifying the standardized direct effects of each factor regarding the variables taken as criterion, modeled in one unique latent variable. The decision to do this analysis came because bivariate correlations can mask the shared variance between factors. In accordance with the results, only the factors of self-efficacy for decision making and self-efficacy for the positive school climate showed positive and significant relationships. That is to say, in the bivariate correlations, the effects found of the rest of the factors regarding the latent variable were due to the shared variance of the said factors with self-efficacy for decision making and self-efficacy for the positive school climate.

Finally, significant differences were not found in the dimensions of collective teacher self-efficacy for any of the socio-demographical, academic, or institutional variables explored (gender, type of administration, class they taught, amount of schools they work at, age, and years spent working). This goes in agreement with previous studies except for the variable of years spent working which was sometimes related to collective teacher self-efficacy (Egger, 2006). One possible hypothesis with respect to the absence of significant relationships with these socio-demographic variables could be that collective teacher self-efficacy is emerging at a group level. That is to say, that the aspects of each teacher individually do not contribute in a significant way to its development. This makes necessary to explore other relationships which contribute and 
explain the differences in the construct, especially at a group or institutional level. Some of these variables have already seen themselves related to other studies, like the type of administration of the institution (Cansoy, 2020; Dussault et al., 2008; Karacabey et al., 2020; Meyer et al., 2020; Qadach et al., 2020; Voelkel, 2019), the level of school conflict (Goddard, 2001) or socioeconomic status of the student population that assist that institution (Jean Eells, 2011).

Even though the evidence collected presents limitations like low percentage of male teachers, the partially confirmatory strategy of structural analysis, or the measurement of criterion variables with unique items, the results are promising. Psychometric instruments are essential to achieve a better understanding of the phenomena and to be able to evaluate them from a quantitative perspective. While Collective Teacher Selfefficacy Scale (Sánchez-Rosas et al. (2021)) keeps adding favorable evidence, it could have practical and theoretical applications. That is, it could be used in educational institutions as a diagnostic measure, to help psychologists working in an institution to understand the challenges that institution is facing.

At the same time, Collective Teacher Self-efficacy Scale could be used to find out the relationship between collective teachers self-efficacy and other variables related to teachers, such as individual self-efficacy, which has shown positive relationships to professional development, student-centered instruction (Hwang, 2021), and principals' leadership behaviours (Mehdinezhad \& Mansouri, 2016), and counts with plenty of theoretical development and instruments to measure it. The Scale could be also used to find out the relationship between collective teachers self-efficacy and variables related to the student body, the management team and the community. This information could be valuable in order to design resources to promote collective teacher self-efficacy.

At the same time, the information that is able to be obtained regarding the influence of collective teacher self-efficacy in various variables could influence the design of politics related to education and the teacher's educative process, promoting concrete rules for its development. Thus, progress could be made in strengthening the teaching task and in its recognition as a team task.

\section{REFERENCES}

Aiken, L. R. (1985). Three coefficients for analyzing the reliability and validity of ratings. educational and psychological measurement, Educational and Psychological Measurement, 45(1), 131-142. https://doi.org/10.1177/0013164485451012

Al-Mahdy, Y. F. H., Emam, M. M., \& Hallinger, P. (2018). Assessing the contribution of principal instructional leadership and collective teacher efficacy to teacher commitment in Oman. Teaching and Teacher Education, 69, 191-201. https://doi.org/10.1016/j.tate.2017.10.007

Asparouhov, T., \& Muthén, B. (2009). Exploratory structural equation modeling. Structural Equation Modeling, 16, 397-438. doi: 10.1080/10705510903008204

Bandura, A. (2006). Guide for constructing self-efficacy scales. In Urdan, T., \& Pajares, F. (Ed). Self-Efficacy Beliefs of Adolescents, 307-337. Connecticut, USA: IAP. 


\section{https://doi.org/10.1017/CBO9781107415324.004}

Buonomo, I., Fiorilli, C., \& Benevene, P. (2020). Unravelling teacher job satisfaction: The contribution of collective efficacy and emotions towards professional role. International Journal of Environmental Research and Public Health, 17(3). https://doi.org/10.3390/ijerph17030736

Cansoy, R. (2020). Transformational school leadership: predictor of collective teacher efficacy. Sakarya University Journal of Education, 90-103. https://doi.org/10.19126/suje.569750

Cansoy, R., Parlar, H., \& Polatcan, M. (2020). Collective teacher efficacy as a mediator in the relationship between instructional leadership and teacher commitment. International Journal of Leadership in Education, 1-19. https://doi.org/10.1080/13603124.2019.1708470

Coğaltay, N., \& Karadağ, E. (2017). The effect of collective teacher efficacy on student achievement. In Karadağ, E. (Ed.) The Factors Effecting Student Achievement: MetaAnalysis of Empirical Studies (pp. 215-226). Springer. https://doi.org/10.1007/978-3319-56083-0_13

Cooper, J. D. (2010). Collective Efficacy, organizational citizenship behavior and school effectiveness in alabama public High Schools (Doctoral Theses). Department of Educational Leadership, Policy, and Technology Studies in the Graduate School of the University of Alabama. Tuscaloosa, Alabama.

Dominguez-Lara, S. (2017). Development of a research Self-Efficacy scale: preliminary evidence of validity. Digital Journal of University Teaching Research, 11(2), 308-322. https://doi.org/10.19083/ridu.11.514

Dominguez-Lara, S. (2018). Proposal for cut-offs for factor loadings: A construct reliability perspective. Enfermería Clínica, 28(6), 401 - 402. https://doi.org/10.1016/j.enfcli.2018.06.002

Dominguez-Lara, S., \& Merino-Soto, C. (2018). Testing misspecifications in structural equation modeling. Argentinean Journal of Behavioral Sciences, 10(2), 19-24. https://doi.org/10.30882/1852.4206.v10.n2.19595

Donohoo, J. (2018). Collective teacher efficacy research: Productive patterns of behaviour and other positive consequences. Journal of Educational Change, 19, 323345. https://doi.org/10.1007/s10833-018-9319-2

Dussault, M., Payette, D., \& Leroux, M. (2008). Principals' transformational leadership and teachers' collective efficacy. Psychological Reports, 102(2), 401-410. https://doi.org/10.2466/pr0.102.2.401-410

Egger, K.J. (2006) An exploration of the relationships among teacher efficacy, collective teacher efficacy, and teacher demographic characteristics in conservative Christian schools (Doctoral theses). University of North Texas. Retrieved 20 March, 2021

from 
https://digital.library.unt.edu/ark\%3A/67531/metadc5376/m2/1/high_res_d/dissertation. pdf

Fleming, J., \& Merino-Soto, C. (2005). Measures of simplicity and factorial fit: An approach for the evaluation of factorially derived scales. Journal of Psychology, 23(2), 252-266. $\quad$ Retrieved 1 March, 2021 from http://revistas.pucp.edu.pe/index.php/psicologia/article/view/2150

Gibson, S., \& Dembo, M. H. (1984). Teacher efficacy: A construct validation. Journal of Educational Psychology, 76(4), 569-582. https://doi.org/10.1037/00220663.76.4.569

Goddard, R. (2002). A theoretical and empirical analysis of the measurement of collective efficacy: The development of a short form. Educational and Psychological Measurement, 62(1), 97-110. https://doi.org/10.1177/0013164402062001007

Goddard, R. D., Hoy, W. K., \& Hoy, A. W. (2000). Collective teacher efficacy: its meaning, measure, and impact on student achievement. American Educational Research Journal, 37(2), 479-507. https://doi.org/10.3102/00028312037002479

Goddard, R. D. (2001). Collective efficacy: A neglected construct in the study of schools and student achievement. Journal of Educational Psychology, 93(3), 467-476. https://doi.org/10.1037/0022-0663.93.3.467

Hu, L. T., \& Bentler, P. M. (1999). Cutoff criteria for fit indexes in covariance structure analysis: Conventional criteria versus new alternatives. Structural Equation Modeling, 6, 1-55. https://doi.org/10.1080/10705519909540118

Hunsley, J., \& Marsh, E. J. (2008). Developing criteria for evidence-based assessment: An introduction to assessment that work. In J. Hunsley \& E. J. Marsh (Eds.) A guide to assessments that work (pp. 3-14). Oxford: Oxford University Press.

Hwang, S. (2021). The mediating effects of self-efficacy and classroom stress on professional development and student-centered instruction. International Journal of Instruction, 14(1), 1-16. https://doi.org/10.29333/iji.2021.1411a

Jean Eells, R. (2011). Meta-Analysis of the relationship between collective teacher efficacy and student achievement (Doctoral Theses). Loyola University. Chicago. Retrieved 12 December, 2020 from https://ecommons.luc.edu/luc_diss/133

Karacabey, M. F., Bellibaş, M. Ş., \& Adams, D. (2020). Principal leadership and teacher professional learning in Turkish schools: examining the mediating effects of collective teacher efficacy and teacher trust. Educational Studies, 1-20. https://doi.org/10.1080/03055698.2020.1749835

Kirby, M. M., \& DiPaola, M. F. (2011). Academic optimism and community engagement in urban schools. Journal of Educational Administration, 49(5), 542-562. https://doi.org/10.1108/09578231111159539

Klassen, R. M. (2010). Teacher stress: The mediating role of collective efficacy beliefs. 
Journal of Educational Research, 103(5), 342-350. https://doi.org/10.1080/00220670903383069

Klassen, R. M., Tze, V. M. C., Betts, S. M., \& Gordon, K. A. (2011). Teacher efficacy research 1998-2009: signs of progress or unfulfilled promise? Educational Psychology Review, 23(1), 21-43. https://doi.org/10.1007/s10648-010-9141-8

Leanne, M., Resendes, M., Scardamalia, M., \& Dobbie, K. (2019). The knowledge building network pilot project: An exploration of emergent designs to enhance collective teacher efficacy. In Computer-Supported Collaborative Learning Conference, CSCL (Vol. 1, pp. 81-87).

Leithwood, K., Sun, J., \& Schumacker, R. (2019). How school leadership influences student learning: a test of "The Four Paths Model". Educational Administration Quarterly. https://doi.org/10.1177/0013161X19878772

Lim, S., \& Eo, S. (2014). The mediating roles of collective teacher efficacy in the relations of teachers' perceptions of school organizational climate to their burnout. Teaching and Teacher Education, 44, 138-147. https://doi.org/10.1016/j.tate.2014.08.007

Lloret-Segura, S., Ferreres-Traver, A., Hernández-Baeza, A., \& Tomás-Marco, I. (2014). Exploratory Item Factor Analysis: A practical guide revised and updated. Annals of Psychology, 30(3), 1151-1169. https://dx.doi.org/10.6018/analesps.30.3.199361

Malinen, O. P., \& Savolainen, H. (2016). The effect of perceived school climate and teacher efficacy in behavior management on job satisfaction and burnout: A longitudinal study. Teaching and Teacher Education, 60, 144-152. https://doi.org/10.1016/j.tate.2016.08.012

McDonald, R., \& Ho, M.-H. R. (2002). Principles and Practice in Reporting Structural Equation Analyses. Psychological methods, 7(1), 64-82. 64-82. https://doi.org/10.1037/1082-989X.7.1.64

Merino-Soto, C. (2016). Perception of item clarity: Comparison of judgments between students and expert judges. The Latin American Journal of Social Sciences, Childhood and Youth, 14(2), 1469-1477. https://dx.doi.org/10.11600/1692715x.14239120615

Mehdinezhad, V., \& Mansouri, M. (2016). School principals' leadership behaviors and its relation with teachers' sense of self-efficacy. International Journal of Instruction, 9(2), 51-60. http://www.e-iji.net/dosyalar/iji_2016_2_4.pdf

Merino-Soto, C. (2018). Confidence interval for difference between coefficients of content validity (Aiken's V): A SPSS syntax. Annals of Psychology, 34(3), 587-590. https://doi.org/10.6018/analesps.34.3.283481

Merino-Soto, C., \& Livia Segovia, J. (2009). Confidence intervals for the content validity: a visual basic computer program for the Aiken's V. Annals of Psychology, 25(1), 159-161. $\quad$ Retrieved $10 \quad$ January 2021 from 
https://dialnet.unirioja.es/servlet/articulo?codigo=2973711

Meyer, A., Richter, D., \& Hartung-Beck, V. (2020). The relationship between principal leadership and teacher collaboration: Investigating the mediating effect of teachers' collective efficacy. Educational Management Administration \& Leadership. https://doi.org/10.1177/1741143220945698

Olivier, D. F., \& Hipp, K. K. (2019). Leadership Capacity and Collective Efficacy: Interacting to Sustain Student Learning in a Professional Learning Community. Journal of School Leadership, 16(5), 505-519. https://doi.org/10.1177/105268460601600504

Pérez, E., Medrano, L., \& Sánchez-Rosas, J. (2014). Path Analysis: basic concepts and examples. Argentinean Journal of Behavioral Sciences, 5(1), 52-66. https://doi.org/10.32348/1852.4206.v5.n1.5160

Qadach, M., Schechter, C., \& Da'as, R. (2020). Instructional leadership and teachers' intent to leave: The mediating role of collective teacher efficacy and shared vision. Educational Management Administration \& Leadership, 48(4), 617-634. https://doi.org/10.1177/1741143219836683

Sánchez-Rosas, J., Dyzenchauz, M., \& Dominguez-Lara, S. (2021). Validez de contenido de la escala de autoeficacia colectiva docente. Revista Argentina De Ciencias Del Comportamiento, 13(1), 59-72. https://doi.org/10.32348/1852.4206.v13.n1.28132

Skaalvik, E. M., \& Skaalvik, S. (2007). Dimensions of teacher self-efficacy and relations with strain factors, perceived collective teacher efficacy, and teacher burnout. Journal of Educational Psychology, 99(3), 611-625. https://doi.org/10.1037/00220663.99.3.611

Skaalvik, E. M., \& Skaalvik, S. (2016). Teacher stress and teacher self-efficacy as predictors of engagement, emotional exhaustion, and motivation to leave the teaching profession. Creative Education, 7(13), 1785-1799. https://doi.org/10.4236/ce.2016.713182

Skaalvik, E. M., \& Skaalvik, S. (2019). Teacher self-efficacy and collective teacher efficacy: relations with perceived job resources and job demands, feeling of belonging, and teacher engagement. Creative Education, 10(7), 1400-1424. https://doi.org/10.4236/ce.2019.107104

Strahan née Brown, C., Gibbs, S., \& Reid, A. (2019). The psychological environment and teachers' collective-efficacy beliefs. Educational Psychology in Practice, 35(2), 147-164. https://doi.org/10.1080/02667363.2018.1547685

Tschannen-Moran, M., \& Barr, M. (2004). fostering student learning: the relationship of collective teacher efficacy and student achievement. Leadership and Policy in Schools, 3(3), 189-209. https://doi.org/10.1080/15700760490503706

Voelkel, R. H. (2019). Causal relationship among transformational leadership, professional learning communities, and teacher collective efficacy. International 
Journal of Leadership in Education, 1-22. https://doi.org/10.1080/13603124.2019.1690699

West, S. G., Taylor, A. B., \& Wu, W. (2012). Model fit and model selection in structural equation modeling. In R. H. Hoyle (Ed.), Handbook of Structural Equation Modeling (pp. 209-231). New York, NY: Guilford.

Zhang, Z., \& Yin, H. (2017). Effects of professional learning community and collective teacher efficacy on teacher involvement and support as well as student motivation and learning strategies. Education in the Asia-Pacific Region 38, 433-452. https://doi.org/10.1007/978-981-10-3654-5_27

\section{APPENDIX}

\section{TEACHER'S COLLECTIVE SELF-EFFICACY SCALE}

Instruction. We want to know your beliefs about the collective capacity that teachers at your school have to work as a team. Each of the affirmations refers to the whole group of teachers, including yourself. This means that you are not to respond according to your individual capacities or those capacities of a coworker, but the capacity of the whole group to finish certain tasks all together. Use the following scale to numerically value your affirmations. You can use any value from 1 to 10 :

$\begin{array}{llllllllll}1 & 2 & 3 & 4 & & 6 & 7 & 8 & 9 & 10\end{array}$

We the teachers of this school can..

\begin{tabular}{l}
\hline Self-efficacy for decision making \\
\hline 1. Organize ourselves to be heard while making decisions at the school \\
\hline 2. Reach a consensus to express our opinion about important matters for our school \\
\hline 6. Get on the same page about how to communicate our opinion to the leaders of the school \\
\hline 7. Organize ourselves to demand help when facing a problematic situation \\
Self-efficacy for teaching \\
\hline 9. Share effective strategies to better the performance of students with learning difficulties. \\
\hline 10. Develop didactic resources for students to do group work together \\
\hline 11. Share amongst ourselves innovative methodologies to promote significant learning strategies \\
\hline 13. Develop strategies for students to be more dedicated to their own learning together \\
\hline Self-efficacy for familial participation \\
\hline 24. Work together so that families may help their kids with homework \\
\hline 25. Organize activities so that families feel part of the institution \\
\hline 26. Organize meetings to speak with families regarding problems their children are facing at school \\
\hline 27. Establish means of communication that facilitate familial participation \\
\hline Self-efficacy for community participation \\
\hline 31. Design projects which include the participation of community organizations \\
\hline 32. Organize meetings with experts of our community to talk about topics which interest us \\
\hline 33. Create a network of mutual collaboration with different organizations in the community \\
\hline 35. Organize educational activities with the participation of people from outside of the institution \\
\hline Self-efficacy for the positive school climate \\
\hline 38. Establish positive relationships to make the school a safe space \\
39. Create trust regarding teachings amongst the student body \\
\hline 40. Create spaces with group reflection to promote empathetic relationships \\
\hline 42. Guarantee inclusion and respect for diversity amongst all of the teachers \\
\hline
\end{tabular}

